\title{
REVISION:
}

\section{Turnout and the Party System in Canada, 1988-2004*}

\author{
Richard Johnston \\ University of Pennsylvania \\ J. Scott Matthews \\ Queen's University \\ Amanda Bittner \\ University of British Columbia
}

\section{DO NOT CITE WITHOUT AUTHORS' PERMISSION}

* Previous versions of this paper were presented at the 2005 Annual General Meeting of the Canadian Political Science Association, London, ON, and the 2006 Annual General Meeting of the American Political Science Association, Philadelphia, PA. Research for this paper was made possible by the Social Sciences and Humanities Research Council of Canada under grant 410-02-0539, by doctoral fellowships for Matthews and Bittner, and for its long-term support for the Canadian Election Studies. Fred Cutler's help in data acquisition and handling is gratefully acknowledged, as are his comments on various aspects of analysis. Also of great help were comments by Daniel Rubenson, Ben Nyblade, and participants in the UBC Canadian and Comparative Politics Workshop. All of the forgoing are exempted from responsibility for any errors or omissions that remain. 


\section{Turnout and the Party System in Canada, 1988-2004}

Turnout in Canadian national elections declined sharply in the 1990s, especially among young voters. We argue that a prime cause is the parallel decline in electoral competitiveness. We demonstrate this by estimating an encompassing model of turnout, including indicators of party spatial location and riding-level competitiveness embedded in a setup that is sensitive to entering cohorts and the passage of time, broadly in the spirit of Franklin (2004). Data come from the Canadian Election Studies from 1988 to 2004. In addition to its main conclusions, the analysis generates new questions, especially about how voters derive information about competitiveness and about the relative importance of voters' own reckonings and the strategic allocation of resources and effort by parties.

Key words: voting; turnout; competitiveness; youth; Canada. 
Turnout in Canadian elections has plummeted, and the drop has been especially acute among young voters. The argument of this paper is that the proper starting point in analyzing both overall turnout decline and the widening age gap is the dramatic post1988 drop in the competitiveness of Canadian elections. It is also critical that competitiveness was largely restored in 2004 and that the turnout decline abruptly stopped.

In this, our analysis is broadly in line with the general theoretical arguments of Franklin (2004a, 2004b) and Plutzer (2002), and also fits some recent analysis of the Canadian case (see, especially, Pammett and Leduc 2003, 2004). Even so, we deepen analysis of the Canadian case in important ways. First, where Franklin's (2004a) treatment of Canada embodies no competitiveness data below the national level, local competitiveness is central to the case we present here. As well, we refine aspects of Franklin's general argument, including his claims regarding the importance of electoral initiation. And to scholarship specific to the role of electoral competitiveness in Canadian turnout, we add empirical and analytical depth: where existing work has focused on bivariate analysis of single elections, we estimate a fully specified empirical model of turnout encompassing the five elections between 1988 and 2004.

We begin by localizing the turnout drop in history. We then stylize the key changes in the party system as they might bear on turnout and then embed the aggregate factors in an encompassing turnout model that is sensitive to aging and cohort succession. We show that shifts in local electoral competitiveness materially affect turnout as indicated by survey data. The paper closes with a discussion of limitations with the approach and avenues for further exploration. 


\section{Turnout in Canada: Facts and Interpretations}

On the published record so far, the prevailing interpretation of Canada's turnout decline is cultural. An example is the analysis offered by Blais et al. (2004):

The most recent generations are less prone to vote in good part because they pay less attention to politics and because they are less likely to adhere to the norm that voting is a cultural duty. The decline in voting thus reflects a larger cultural change. (p. 234)

This view is shared by Howe (2004), who also emphasizes a general weakening of community ties. And it echoes analyses in other countries (Wattenberg 2000; Dalton 1999, Gray and Caul 2000). ${ }^{1}$ On this view, reversing the trend requires special educational efforts, and reversal may not be possible. This interpretation has at best a modest basis in fact, however. Blais et al. (2004), for instance, provide no time series evidence for such a cultural mechanism, in contrast with the care they lavish on their other analyses.

And where the cultural claim implies a secular trend, the decline in Canadian turnout was catastrophic, largely confined to one decade and sharpest between the 1993 and 1997 elections. Figure 1 plots turnout for elections from 1945 to 2000, where turnout is expressed as the ratio of votes cast to the voting age population. ${ }^{2}$ There is

\footnotetext{
${ }^{1}$ Not all of these authors carry the moral emphasis of Blais et al. 2000, but all see turnout decline as primarily driven by slow-moving extra-electoral factors.

${ }^{2}$ Alternative indicators of turnout - e.g. registered voters as a share of the voting age population, votes cast as a share of registered voters - are imaginable. That said, the post-1988 drop was massive and quite sudden by any indicator. For this paper's purposes, however, the appropriate denominator is the votingage population, as it gives the most plausible localization of shifts within the 1988-2000 period. The basis for the voters list shifted twice between 1988 and 2000 (Black 2005), and so turnout calculated on the list necessarily misspecifies the shifts. The only sensible comparisons over the full period use the voting age population as the base.
} 
evidence of decline before 1993, to be sure. Between 1962 and 1974, turnout dropped nine points on this indicator. But 1974 appears to be an outlier, as little trend appears between 1962 and 1972. Turnout went back up in 1979 and rose again in 1984 and 1988. In the 1984 and 1988 elections, turnout was scarcely different from the 1960s' pattern. ${ }^{3}$ If we compare average turnout for the 1962-8 elections with that for 1980-88, the difference is between 4.5 and 5 points. Compared to the $1960 \mathrm{~s}-80$ s difference, the drop after 1988 was more than twice as large, nearly 14 points. The critical interval for the turnout decline was between 1993 and 1997, when turnout dropped 6.8 points, fully half the total post-1988 decline. The 1988-93 drop was 4.4 points and the 1997-2000 drop was just 2.5 points. Turnout decline stopped abruptly in 2004 .

It does seem natural to ask, then, what happened in the 1990s? In fact, a cataclysm befell the system in 1993, and only in 2004 was much of the damage repaired. The 1993 election was a watershed in the history of the Canadian party system, featuring the effective exit of two nationally-oriented major parties - the Progressive Conservatives (PCs) and the New Democratic Party (NDP) - and the entry of two minor parties with distinctly regional bases of support — the Bloc Québécois in Quebec and the Reform Party in the West (Carty, Cross and Young 2000). As a result, the national popular vote underwent a sudden and dramatic fragmentation—and remained fragmented through 2000 .

In one sense, this fragmentation ought to have increased turnout. This is because, in the language of spatial theory (see, inter alia, Downs 1957; Riker and Ordeshook

\footnotetext{
${ }^{3}$ Note that there is a very suggestive relationship between turnout and the Conservative vote. Turnout tends to surge with the Tory electoral share (note the figures for 1957, 1958, 1972, 1979, 1984 and 1988 - and arguably 2004) and vice versa. This could reflect differential mobilization of protoConservatives. But it could also reflect more widespread anticipation of a resurgence of party competition, a possibility very much in line with the theme of this paper.
} 
1973; Enelow and Hinich 1984), the fragmentation increased the ideological distance covered by the party system. Conservatively-minded voters outside Quebec now could support a much more conservative party than the old Progressive Conservatives. This new alternative, Reform, also catered to western sentiment more efficiently than the PCs ever could. The Bloc Québécois illustrates the same point even more vividly. Before 1993 there was simply no outlet for sovereignist sentiment. With the advent of the Bloc, the federal system now delivered these voters a quite satisfactory alternative.

The increase in the number of parties should, consequently, have had two beneficial effects on the utility that Canadian voters derived from electoral participation. First, the distance voters perceived between themselves and the closest party should have shrunk; voters should have become less alienated, in the sense intended by Riker and Ordeshook 1973 (p.323ff). At the same time the typical voter's distance to the party furthest away should have increased. This raises the stakes and, in Riker-Ordeshook terms, voters should have become less indifferent. Below we show that alienation and indifference did drop in 1993 and that both shifts ought, ceteris paribus, to have increased turnout. ${ }^{4}$

It seems clear, however, that party-system fractionalization, with all its pathways of effect taken into account, decreases turnout (Jackman, 1987; Blais 2000, Table 1.3; Gray and Caul 2000; Franklin 2004a). And facets of the 1993 shift point to diminished appeal for voting. In particular, uncertainty about electoral victory was reduced both nationally and locally. Crucial here is the fact that the fractionalization of national

\footnotetext{
${ }^{4}$ Note that this treatment of alienation and indifference sets us apart from literature that emphasizes a secular increase in alienation or indifference since at least the 1960s (see, for example, Abramson 1983; Dalton 1999; Herring 1979; and Macke 1979). For these scholars, among others, alienation and indifference represent diffuse orientations toward the political system as a whole (per Almond and Verba 1963), rather than perceptions of specific attributes of the party system.
} 
results was much greater among parties other than the Liberals. As a result, only the Liberal party was poised to win in the country as a whole; the sole question was whether or not the party would secure an outright majority of seats. At the same time, national shifts masked even more dramatic local displacements. Although the Liberals lost ground overall, they became overwhelmingly dominant in Ontario. Although the two new parties, Reform (later the Alliance) and the Bloc Québécois, never seriously contested the national result, they commanded very strong regional bases. Two old parties, the Progressive Conservatives (PCs) and the New Democratic Party (NDP), were weakened nationally and overshadowed locally. On average, winners' margins went up as did the percentage of MPs representing outright majorities of their constituents. Locally and nationally, then, the system became less competitive. On the logic of Franklin (2004a), the system was ripe for a turnout drop. ${ }^{5}$

\section{Modeling}

As just mentioned, different elements in the 1990s pattern worked at odds with each other as they affected turnout. On one hand, Canadians should have become more engaged with the choices, and so more likely to turn out. On the other hand, Canadians may have been frustrated at the increased difficulty in translating those choices into parliamentary seats. Using data from the Canadian Election Studies, 1988 to $2004,{ }^{6}$ we evaluate both possibilities in Figure 2.

\section{Perceptions of the Party System}

\footnotetext{
${ }^{5}$ [ REFERENCE DELETED ].

${ }^{6}$ Details in Appendix.
} 
The top panel focuses on perceived benefits of party victory in the election. The utility that voters might derive from the various choices can be expressed in two ways: alienation, how far the respondent is from his or her closest party; and indifference, how much the respondent prefers his or her favourite party over the least favourite one. Our indicators of each variable derive from respondents' expressions of warmth toward each party, originally expressed on 100-point "feeling thermometers." The 100-point scales gauge perceived proximities and can be used to articulate voters' space of alternatives. Alienation is simply indicated by:

$$
\left(100-\max \left(U_{i}\right)\right) / 100,
$$

where $U_{i}$ is the rating of the $i^{\text {th }}$ party on the 100-point scale. Indifference is indicated by:

$$
\left(100-\left(\max \left(U_{i}\right)-\min \left(U_{j \neq i}\right)\right)\right) / 100 .
$$

Both indicators have been compressed to the 0,1 interval for ease of interpretation.

By these indicators, according to Figure 2, Canadians have become less alienated and less indifferent to the party system. The shift seems very small but this is an artifact of coding. The 1988/2000 contrast is clearly significant by the t-test at the 0.05 criterion; over the shorter intervals, the difference is on the border of significance, closer to the line in 1993 than in 1997. More striking are shifts in indifference, which drops steadily from 1988 to 1997, with a modest rebound in 2000. Every contrast with 1988 is highly significant. 2004 is a partial reversion to earlier patterns. Indifference did not increase but alienation certainly did. The latter effect reflects the merger of the Alliance and the 
Progressive Conservatives into the new Conservative party: too far to the left for many former Alliance supporters, too far to the right for many former PCs. ${ }^{7}$

\section{$\underline{\text { Competitiveness }}$}

Franklin (2004a , 2004b) considers competitive conditions both nationally and locally. We suspect that the most important post-1988 shift in the Canadian case is the national one. From 1993 to 2000 there was never any real sense that the Liberals would lose the election. Critically, in 2004 that sense was restored (and the Conservative victory in 2006 validated the 2004 apprehensions). It is worth noting that the terms of Liberal uncertainty are not quite captured by Franklin's (2004a) rendering of national competitiveness. The Liberals' post-1993 margins over their rivals were not unusual by historical standards, and the party's seat majorities were not lopsided. In that sense the system was not less competitive nationally than before. The problem was that between 1993 and 2003, it was impossible to imagine successful coordination on the opposition side. If we were to implement a national level measure, it would have to differ subtly from those in Franklin (2004a). We do not include such a measure, however, for reasons that should be obvious: the indicator would take only five values, one for each of the five elections.

What we can do, however, is give unprecedented nuance to variation across local constituencies. The drawing power of first-past-the-post elections is powerfully constrained by the vulnerability of local contests to one-sided results. Elections under proportional formulae do not tend to exhibit this vulnerability. Franklin (2004a) captures

\footnotetext{
${ }^{7}$ As it happens, the perceptual shift fits equivocally into the age structure, for young voters are less alienated than older ones but more indifferent. The essence of the matter is that young voters rate all parties more highly on average than older voters do.
} 
this with a mean local-margin variable that is switched on only for plurality systems, but for Canada he claims a lack of data (p. 232). This paper remedies the lack.

As Figure 2 shows, local competitiveness became problematic in the Canadian case. The Figure employs the competitiveness index devised by Endersby, Galatas, and Rackaway (2002). The measure has already been used in the Canadian context, where it has been found to outperform more traditional measures, such as the raw vote margin or two party margin, in an analysis of riding-level turnout in the 1993 and 1997 federal elections (Endersby, Galatas and Rackaway 2002). The equation for the constituencylevel competitiveness index is as follows:

$$
c_{k j}=k^{k} \prod_{i=1}^{k} p_{i j}
$$

where $c_{k j}$ is competitiveness among the $k$ parties in constituency $j$ and $p_{i j}$ is the proportion of the total votes cast for the $i$ th party in the $j$ th constituency. Taking the product of these values makes the index a function of the degree of equality among parties' shares: the more equal, the more competitive. The $k^{k}$ term sets index values to the 0,1 range for all values of $k$. The number of parties, $k$, can in principle take on a range of values as desired by the researcher, such as the total number of parties (or candidates) on the ballot or the "effective" number of parties. We adopt the same approach as Endersby et al. (2002) and set $k$ equal to the effective number of parties in the constituency, rounded to the nearest integer. ${ }^{8}$

By this standard, as Figure 2 shows, the Canadian system became less competitive in 1993, recovered ground in 1997, and hit bottom in 2000. The 2004

\footnotetext{
${ }^{8}$ The effective number of parties originates with Laakso and Taagepera (1979) and is calculated as $1 / \sum\left(p_{i j}{ }^{2}\right)$, where $p_{i j}$ is defined as in the body of the text.
} 
election restored some of the old competitiveness but not all. Figure 2 also shows that shifts in competitiveness were not geographically uniform. Atlantic Canada, Saskatchewan, and Manitoba are not singled out as in those places the system remained almost as competitive as before, especially in 1997. Alberta does not appear because it remained almost as uncompetitive as before. ${ }^{9}$ The national pattern was driven mainly by shifts in Ontario and BC, the largest and third largest provinces, respectively. In 1988, Ontario elections were more competitive than the national average. In 1993, they were less so. In 2000 and 2004, they tracked the national pattern closely. British Columbia exhibited bigger shifts: it went from being at the national average to well below it, only to bounce well above the national average in 2004. Much of the BC pattern is a reflection of the fortunes of the NDP, which collapsed in 1993 and recovered in 2004. Quebec followed a quite different trajectory. In that province, 1993 did not reduce competitiveness in the province and 1997 only increased it. In 1993, the Bloc Québécois essentially supplanted the PCs as the chief rival to the Liberal Party. The 1997 surge reflected the temporary resurgence of the PCs under Jean Charest. The PC collapse in 2000 and the retreat of the Bloc Québécois into the province's hinterland left local races in Quebec dramatically less competitive than before and 2004 did not alter this situation. $^{10}$

\footnotetext{
${ }^{9}$ In fact, Alberta became slightly more competitive in the 1990s with the rise of the Liberal vote that enabled the party to win two seats each year from 1993 to 2004.

${ }^{10}$ By way of validation, consider the following crude but simple indicators. In 1988, less than one Ontario respondent in five and only one $\mathrm{BC}$ respondent in eight lived in a riding represented by an MP who won an outright majority of votes. In 1993 and 2000, more than half of Ontario respondents were represented by majority-winning MPs; the number dipped in 1997. In BC, the number jumped to one in four in 1997 and one in two in 2000. In 1988, the median Ontario respondent lived in a riding with a ten-point gap between the first and second place party; by implication, half of Ontarians lived in even closer seats. In 1993, the median gap was about 25 points, and it stayed at that level in 1997 and 2000. From 1993 on, only $13 \%$ of Ontario respondents lived in seats with 10-point or smaller margins. The median gap in BC
} 
This interaction between space and time is critical to our interpretation. If competitiveness declined uniformly, our case would be vulnerable to the criticism that competitiveness is just some combination of space and time by another name. Put another way, we would just be capturing Canadian political "geology" and dignifying it with a summary statistic. The fact that competitiveness went down (and then back up) in some places and not others makes it plausible as a factor in its own right.

\section{Learning to be a Non-Voter}

The modeling discussion to this point serves an account of overall turnout decline but not of a widening age gap. To complete the task we need to model the succession of political generations as they experience varying degrees of competitive pressure. According to Franklin (2004a) and Plutzer (2002), anything that produces temporal variation in political outcomes should have a particularly strong effect on young voters. These authors resurrect models of voting behaviour that go back to the Columbia School (see especially McPhee and Ferguson 1960) as interpreted by Butler and Stokes (1969), and extend them to turnout. A critical fact is that one can learn to be a non-voter, and make this a lesson for life. Franklin argues for a "rule of three:" a citizen's first three elections play a critical role in determining his or her subsequent place in the political structure. Since the enfranchisement of 18-year olds, the "rule of three" points to the experiences of the late teens through the mid- to late-20s.

Although we follow Franklin's basic logic, we modify it on frankly empirical grounds. Preliminary work with the Canadian data suggests a "rule of two." We submit that we are on no worse ground, theoretically speaking, than Franklin, and possibly on 2000 . 
better ground empirically. Close reading of the standard sources indicates no hard evidence for three-election cycles. ${ }^{11}$ We feel comfortable, then, defining newly eligible voters as anyone for whom the election of a given year is the first or second opportunity to cast a ballot. Depending on lapse of time since the preceding election, the newly eligible voter age range varies from 18-24 to 18-26.

Newly eligible voters need to be represented both by a dummy variable and by a dummy-variable interaction with competitiveness. Not only are newly eligible voters less likely to turn out, they should be highly sensitive to short-run factors both of attraction and repulsion. On the logic of the interaction setup, the coefficient on the "newly eligible voter" dummy variable refers to newly eligible voters in absolutely uncompetitive places, the main effect of competitiveness refers to impact among eligible voters who are not new, and the interaction coefficient captures the difference in competitiveness impact between newly eligible voters and others. The competitiveness effect among newly eligible voters themselves is the sum of the two competitiveness coefficients. $^{12}$

\footnotetext{
${ }^{11}$ In Plutzer (2002), for example, the early adulthood time path of gains is presented as a latent growth model. The second derivative of turnout on age is always negative but it is not obvious where qualitatively interpretable gains can be said to stop. Besides, the time path clearly varies across subcategories of young adults. The study with the largest young-adult sample, Highton and Wolfinger (2001), strongly suggests that about two-thirds of all turnout gain between ages 18 and 24 occurs in the first half of that sequence.

${ }^{12}$ A comment on possible interactions that the setup suppresses. First, if newly-eligible voter status interacts with competitiveness, should it not also interact with the other party-system indicators, alienation and indifference? Estimates for such a model reveal that these interactions are far from statistical significance, although coefficient estimates are in the appropriate direction - that is, the model suggests that alienation and indifference effects maximize among newly eligible voters (results available from the authors on request). Furthermore, and importantly, the addition of these interactions leaves the structure of competitiveness effects undisturbed. For these reasons, then, interactions between alienation and indifference and the newly eligible voter dummy are suppressed. Second, should the party system variables interact among themselves, that is, should competitiveness interact with the thermometer-based indicators? Arguably, such an interaction is indicated by the canonical formulation of the calculus of voting in Riker and Ordeshook (1973). But our utility indicators are not those of the calculus of voting, even though they have the same intellectual paternity. And there is powerfully suggestive evidence that additive models outperform interactive ones (Blais 2000, pp. 73-4).
} 


\section{$\underline{\text { Covariates }}$}

Although our focus is on the intersection of party system factors and demography, estimation requires a fully specified model. The full specification has two beneficial effects: it stabilizes the overall estimation; and it purifies the centrally interesting demographic effects. Accordingly, to the above indicators of alienation, indifference, competitiveness and newly eligible voter status, we add a list of covariates derived from work on the social basis of turnout (see, especially, Uhlaner 1989; Blais 2000; Blais et al. 2004; Brady, Verba, and Schlozman 1995; Rosenstone and Hansen 1993; Verba, Schlozman, and Brady 1995). The list includes the following: age (as both a linear and quadratic term), an income scale ${ }^{13}$, education (degree-holders and high school dropouts vs. others), race (visible minorities vs. others), gender (woman=1), religion (Christians vs. others), union membership and marital status (those married and "partnered" vs. others). Coefficient estimates for these variables are not reported or discussed in text. It will suffice to note that results here, in most respects, comport with previous findings. $^{14}$

\section{Results}

We estimate our model of turnout ${ }^{15}$ in four steps. Equation I includes only demographic controls and fixed effects for election years. To this setup, equation II adds the indicators of alienation and indifference. Equation III then incorporates the

\footnotetext{
${ }^{13}$ The variable derives from a ten-level scale, where the bottom-most category includes all those earning less than $\$ 20,000 /$ year, the top-most category includes all those earning $\$ 100,000 /$ year or more, and inbetween categories are bounded at $\$ 10,000$ intervals. Missing data are imputed by linear interpolation (roughly 12 per cent of observations). In the analysis, the scale runs from 0 to 1 .

${ }^{14}$ Full results and details available from the authors.

${ }^{15}$ This is self-reported turnout, as measured in the post-election wave of each study.
} 
measure of competitiveness, and equation IV, the full model, includes an interaction between this measure and the newly-eligible-voter dummy.

Results for equation I indicate that survey reports reflect real world dynamics in turnout—although not turnout levels—relatively faithfully. Predicted turnout falls in each year following 1988, starting with a modest drop in 1993 . The decline accelerates in 1997, continues - if slows - in 2000, and then arrests by 2004. In broad outline, the estimates mimic electoral history as it actually unfolded (see above, Figure 1). Of course, as is typical of survey estimates of turnout, levels of turnout are radically overestimated: the model predicts ${ }^{16}$ turnout rates of 93 percent in 1988, 92 percent in 1993, 87 percent in 1997, 86 percent in 2000, and 87 percent in 2004. The overestimates principally reflect the reluctance of survey respondents to admit the socially undesirable - that is, to admit that they did not vote. Apart from vitiating the usefulness of point predictions based on these data, it bears noting that this compression of variance in measured turnout works against the rejection of almost any null hypothesis, as key coefficients in this paper are likely to be underestimated. Even so, results for the model confirm that the CES data get the over-time change approximately right—a necessary condition for assessing the role of the party system in these dynamics.

Estimates for equation II show that alienation and indifference both matter, and in theoretically expected ways. An increase in either produces a decrease in turnout, with the largest effect of the two emanating from alienation. A unit shift on this variable would produce a massive 14 point drop in turnout; a comparable shift on the

\footnotetext{
${ }^{16}$ Unless otherwise indicated in text, predictions in this section of the paper are derived using the CLARIFY extension to Stata (King et al. 2000; Tomz et al. 2003), holding other variables in the model at their mean values.
} 
indifference measure would produce a 9 point drop. Of course, this is an implausible range of variation for both variables. Over the analysis period, the largest shift in alienation, the drop from 0.35 to 0.33 between 1988 and 2000, produced an increase in turnout of just 0.2 points. The largest shift in indifference - the drop from 0.67 to 0.48 between 1988 and 1997-produced an increase of nearly two points. Note also the impact on the fixed year effects as these variables enter the model. For each year, the coefficient swells. This suggests that, as expected, dynamics in alienation and indifference worked against the grain of turnout decline over the nineties. That is to say, the fall in electoral participation would have been even more precipitous were it not for coinciding declines in alienation and indifference.

Competitiveness, the factor whose shift gives most promise of accounting for the sudden turnout drop, enters at the next stage, in equation III. At this stage, it enters only as a "main effect"; no account is taken of the differential sensitivity of the young. The point here is to establish the overall power of the induction. Certainly, the impact of competitiveness is significant by any statistical criterion. Substantively, its impact is modest but indicative. A unit increase in competitiveness, for instance, produces roughly a 4 percentage point gain in turnout. A more plausible evaluation of this effect is to consider the actual competitiveness shift from 1988 to 2000, as indicated by the mean values in Figure 2. The model estimates suggest that this shift would, other things equal, decrease turnout by more than half a point. The 1988-2000 shifts estimated for Ontario and $\mathrm{BC}$ respondents would be 0.8 points. The Canada-wide gain in competitiveness in 2004 should have increased turnout by 0.3 points. These are not absolutely large values, of course. But the overall estimated drop in the CES was only about five points, and even there, we suspect that misreporting biases estimated effects 
toward zero. ${ }^{17}$ And importantly, the entry of competitiveness accounts for a nontrivial — if modest—share of the over-time drop in turnout: looking across equations II and III we see coefficient estimates for the survey years decline in every case.

Newly eligible voters stand out only modestly in equations I through III, with a coefficient that is negative but smaller than its standard error. The drama starts when newly eligible voter status interacts with competitiveness, in equation IV. When this happens, the main effect of competitiveness drops by about half and falls from statistical significance. Newly eligible voters now stand out clearly, as the main effect on that status is now highly significant and substantively large (by the standards of the domain, at least). What this means is that a newly eligible voter in an absolutely uncompetitive place who is otherwise identical to a seasoned voter would be roughly 9 points less likely to turn out. Critically, the coefficient on the interaction term is larger than either of the main effects and is double its standard error. Taken at face value, the interaction coefficient implies that newly eligible voters, if they were otherwise identical to other voters, would be almost four times as sensitive to the 1988-2000 decline in electoral competitiveness. $^{18}$

Of course, other things cannot be equal by definition. In particular, newly eligible voters are defined as younger than the others. So Figure 3 gives a visual sense of the differential susceptibility of newly eligible voters and others, with demographics set

\footnotetext{
${ }^{17}$ As Table 2 indicates, standard errors are "robust," estimated with the Huber-White sandwich correction for clustering. Competitiveness is not unique to each individual but is identically measured for all individuals in a given constituency in a given year. Adjacent constituencies tend to have similar values as do many constituencies themselves over successive years. As a result, standard errors without correction will be biased downward. More ambitious setups, notably hierarchical modelling, hardly seem warranted. Even with clustering by constituency, the number of distinct competitiveness values is over 1200 (over 250 constituencies represented in the sample each year times four years).

${ }^{18}$ Conditioning competitiveness effects this way, moreover, leads to further-albeit small—reductions in the fixed effects for the survey years.
} 
at mean values for the respective subgroups. For each group, the predicted turnout, along with $99 \%$ confidence intervals, is then ranged across values of competitiveness. The key point is the difference in slopes. Over the range of realistic competitiveness variation, say, between 0.45 and 0.75 , the impact of competitiveness is over sixteen times greater for newly eligible voters than for others.

Figure 4 shows the impact of recent history another way, with year-by-year plots of age-specific turnout reports. The overall 1988-2000 reported-turnout drop in the middle-aged core of the electorate, say among 50-year-olds, was about two percentage points. In the youngest age groups, in contrast, the drop was about twenty points. Put another way, a voter coming of age in 1988 was about twenty points less likely than a 50-year-old to claim to have voted. In 2000, the gap was almost 40 points. But 2004 may have reversed the process. The age-specific line for that year roughly splits the difference between the 1988-93 pattern and that of 1997-2000. The gain in turnout noted by Elections Canada (2004) was overwhelmingly the product of remobilization among newly eligible voters.

Both the drop and the gain in newly eligible voters' turnout are the products of interaction between a life-cycle element and a period effect. The life-cycle element is newness, relatively speaking, to the electorate. There is overlap, of course, between elections and newly eligible voter status. Some voters who were newly eligible in 1988 were still newly eligible by our definition in 1993. But many were not, and none who were newly eligible in 1988 were still newly eligible in 1997, and so on. So "newly eligible voter" is a transient status, an indicator of the earliest stage in the political life cycle. The period effect is the sudden shift in competitive conditions. Of such lifecycle/period interactions are cohort effects born. Voters who began coming of age in the 
1990s or who were still coming of age as the decade began were exposed to a political world in which competition was weak, in which the local result was commonly a foregone conclusion. This may be a generation that learned not to vote, notwithstanding its enhanced sense of the stakes in one party's success versus another's. The system's renewed competitiveness, with the rebirth of a Canada-wide Conservative party, gives reason for hope. ${ }^{19}$ But renewed competitiveness may have come too late for the $1990 \mathrm{~s}$ cohort. Turnout will almost certainly increase for this group (Plutzer 2002), but it is unlikely to eliminate the gap between that group and comparable cohorts in earlier (and possibly later) periods. ${ }^{20}$ Thus, if the drop in turnout has been arrested and turnout growth is now on the horizon, the recovery will be slow.

\footnotetext{
${ }^{19}$ The Chief Electoral Officer detects a hopeful glimmer, and his interpretation is broadly consistent with the logic of this paper. In his speech to the Centre for Research and Information on Canada (CRIC) Research seminar on the political engagement of Canadian youth, Ottawa, 1 October, 2004, Mr Kingsley said, "Exercising an authority granted to the Chief Electoral Officer, my Office conducted a study to determine the rate of turnout by age group, using a random sample of polling divisions selected from electoral districts in every province and territory. Based on the lists of electors used on election day in each of the selected polling divisions, we were able to estimate the rate of turnout by age group. The analysis, which involved some 95,000 voters in total, has a statistical reliability of $+/-4 \%, 19$ times out of 20 , when the results are generalized to the entire Canadian voting age population."

"The results of this new analysis are quite remarkable - and encouraging, relatively speaking. For the youngest group of electors - the 18-211/2-year-olds - for whom June 28 was the first federal general election in which they were eligible to vote, the turnout rate was $38.7 \%$. I should point out that the denominator for this rate of turnout is the total population of $18-21 \frac{1}{2}$-year-olds who were eligible to vote."(Kingsley 2004, pp. 16-17). Full text of the speech can be found at: http://www.elections.ca/content.asp? section $=$ med\&document $=0$ oct $0104 \&$ dir $=$ spe $\&$ lang $=$ e\&textonly=false

${ }^{20}$ Just such a possibility is discernible in Elections Canada's research: "Interestingly, for the next oldest group of electors in our study $\left(21 \frac{1}{2}-24\right)$ - those who had been eligible to vote for the first time in 2000 the turnout rate in 2004 was slightly lower than that of the youngest group, at $35.4 \%$ (however, the difference falls within the margin of error). For the others, the rate of turnout rises steadily as we move up the age groups - to a high of $75 \%$ among the 58-67-year-olds...." (Kingsley 2004, p. 17).
} 


\section{Conclusion: Directions for Future Research}

Although we make a compelling case for the impact of competitveness on turnout and for the interaction of competitiveness with voter initiation, this paper represents only a start. We account for only a modest fraction of the meagre turnout drop in the CES. We have glossed over the exact time path of region-specific competitiveness shifts. We have similarly glossed over the spatial component of variation in the dependent variable, in turnout. And we have said little about mechanisms.

Competitiveness did not drop in every province at the same pace. Indeed, it did not shift much or at all in some places. Within-province variation was also considerable, and bears exploration. Although we do not dwell on it, it is also true that the turnout drop was not uniform either spatially or temporally. Quebec in 1993 actually experienced a turnout surge. Not only did competitive conditions in that province not worsen, but the arrival of the Bloc reduced both alienation and indifference. That turnout surged does not invalidate our general claim. Indeed it seems like precisely the exception that proves the rule. It is entirely possible, more generally, that when this level of detail is brought in focus, estimated effects will be all the more powerful.

Then again, the detail may be misleading, for it would imply perceptual variation within provinces that may be implausible, given the structure of media markets. Or it might imply a similarly implausible instant updating of strategic information. These concerns take us directly to mechanisms. This paper does not really posit a mechanism 
for translating strategic circumstance into behaviour; it identifies the start and the end of the causal chain but not the intervening links. Two basic avenues require exploration.

One sees voters themselves as key strategic actors. As this paper uses the indifference/alienation language of Riker and Ordeshook (1973), it might be taken also to imply that the "calculus of voting" is at work. Riker and Ordeshook emphasize that utility differences between parties should be discounted for the probability that one's vote will actually be decisive. Blais (2000) chronicles the uneven fate of this proposition and Franklin (2004a) makes clear that any operable translation of it must be highly contingent on constitutional form. Our own rendering of voters' motives keeps strategic considerations (competitiveness) and substantive considerations of utility (indifference and alienation) strictly separate. This crude treatment may actually be adequate to voter psychology, but we do not know yet.

It seems clear that voters do process strategic information. Cox and Munger (1989), whose objective is to show that party effort produces much of the apparent strategic variation in turnout, nonetheless also conclude that some of the work is done by voters themselves. If so, where do voters get the information? In 1993, for example, how at mid-campaign would a voter know that the Progressive Conservative party would get only two seats or that the Liberal party would sweep Ontario? The task may not have been impossible but the costs of the information would be very steep. This would be especially true at the local level, where strategic reasoning is supposed to occur in the ideal case. So any model that relies on voters must be sensitive to lags in updating. It is possible that the real strategic payoff from 1993 information occurred in 1997. It is a striking — and awkward — fact that the biggest turnout drop was between 1993 and 1997, even though 1997 was a sharply more competitive election than either 1993 or 2000. A 
model focussed on voters should also be sensitive to the geographic scope on which information is gathered by, say, media sources. The highest volume of poll information is national. Even though this may not be strictly relevant to a locally-based calculus, it may be all the voter can get. If regionalized information is offered, it is unlikely to be below the level of the province. In $\mathrm{BC}$, for example, such information may be highly misleading about the divergent circumstances of the Lower Mainland and the Interior, not to mention Vancouver Island. Such stories can be multiplied. By implication, competitiveness indicators that instantly update microscopically local variation may come in at too low a level of spatiotemporal aggregation.

But this kind of microscopic instantaneity can in principle be achieved along another causal pathway: party effort. Parties certainly have an incentive to economize on resources, in particular not to waste them on seats that cannot be won or cannot be lost. Parties should have a better sense than voters do of which seats these are. More generally, a theme that emerged in the participation literature of the 1990s is that much turnout is the result of mobilization — citizens engage in political acts because they are recruited (Verba et al. 1995; Rosenstone and Hansen 1993). Some of this recruitment is, so to speak, chronic, assisted by selective social incentives to participate- through social networks and social belonging (Rosenstone and Hansen, 1993: p.179; see also Uhlaner 1989). But some may be the result of party initiative. Party effort may have been a factor in the gradual pre-1988 decline in turnout; certainly Rosenstone and Hansen lay great emphasis on it for the US case and their account accords with anecdotal evidence of Canadian parties' increased difficulty in putting canvassers on the street. But this causal link can also account for sudden shifts. Rosenstone and Hansen (1993: p.169) note that mobilization activity tends to be most intense when the race is 
close, such that increased participation among certain groups will make a big difference. And of course, this was the central point in Cox and Munger (1989).

The task before us should be clear, to explore both the perceptual and informational components of voters' own choices and the mobilization efforts of parties. As we follow these paths, we should not be surprised if they lead us in unexpected directions. But this paper makes a strong case for where we should start: with shifts in competitive conditions. What is more, we show that competitive shifts bear with special force on the citizens who are most vulnerable to period effects. The evidence we marshal is circumstantial but strong.

\section{Appendix: Data Sources}

\section{Aggregate Turnout}

Data underlying Figure 1, except for registered voters in 2000, are taken from the International Institute for Democracy and Electoral Assistance (IDEA) website, http://www.int-idea.se/Voter_Turnout/index.html. Registration for 2000 is taken from Elections Canada's online report on the 2000 election, Table 4, "Voter turnout for the 2000, 1997, 1993 and 1988 general elections," http://www.elections.ca/gen/rep/37g/table4 e.html. The IDEA calculation uses earlier Elections Canada data, which overcounted the number of true registered voters in 2000. The overcount resumes in 2004, for which Elections Canada has not yet supplied corrected data.

\section{Individual Characteristics}

All individual-level data are from the 1988, 1993, 1997, 2000, and 2004 Canadian Election Studies. Principal Investigator for the 1988 and 1993 studies was 
Richard Johnston. Co-investigators for 1988 were André Blais, Henry E. Brady, and Jean Crête, and for 1993, Blais, Brady, Elisabeth Gidengil, and Neil Nevitte. Principal Investigator for the 1997, 2000, and 2004 studies was Blais. Co-investigators for 1997 and 2000 were Gidengil, Nevitte, and Richard Nadeau. For 2004, Nadeau dropped out and Joanna Everitt and Patrick Fournier came on board. Fieldwork for each study was conducted by the Institute for Social Research, York University, with project management by David Northrup.

\section{Competitiveness}

Constituency-level electoral data were obtained from the Library of Parliament through the Library's internet resource 'History of the Federal Electoral Ridings since 1867,' located at: http://www.parl.gc.ca/information/about/process/house/hfer/hfer.asp? $\ldots$ Language $=$ E. Electoral data were then merged to the Canadian Election Study survey data. For 1988, respondents were assigned to Federal Electoral Districts (FEDs) on the basis of self-reported riding names (CES 1988 items $d 12$ and $x m 1$ ). For 1993 and 1997, FED names and codes were supplied by Fred Cutler at the University of British Columbia. These data were available for respondents who provided valid six-digit postal codes that were unique within FEDs - respondents who provided valid postal codes that straddled more than one FED were excluded. This practice excludes respondents essentially at random, and so is not problematic for our analysis. For 2000 and 2004, FED names and codes for all respondents came bundled with the CES data. 
Table 1. Turnout, Spatial Perceptions and Competitiveness, 1988 to 2004

\begin{tabular}{|c|c|c|c|c|}
\hline & $\mathrm{I}$ & II & III & IV \\
\hline Alienation & -- & $\begin{array}{c}-1.341 * * * \\
(0.203)\end{array}$ & $\begin{array}{c}-1.330 * * * \\
(0.203)\end{array}$ & $\begin{array}{c}-1.324 * * * \\
(0.203)\end{array}$ \\
\hline Indifference & -- & $\begin{array}{c}-1.057 * * * \\
(0.160)\end{array}$ & $\begin{array}{c}-1.069 * * * \\
(0.161)\end{array}$ & $\begin{array}{c}-1.072 * * * \\
(0.161)\end{array}$ \\
\hline Competitiveness & -- & -- & $\begin{array}{c}0.420 * * \\
(0.188)\end{array}$ & $\begin{array}{c}0.241 \\
(0.206)\end{array}$ \\
\hline Comp. * Newly Eligible & -- & -- & -- & $\begin{array}{c}0.978 * * \\
(0.463)\end{array}$ \\
\hline Newly Eligible & $\begin{array}{l}-0.081 \\
(0.124)\end{array}$ & $\begin{array}{l}-0.117 \\
(0.125)\end{array}$ & $\begin{array}{l}-0.124 \\
(0.125)\end{array}$ & $\begin{array}{c}-0.676^{* *} \\
(0.288)\end{array}$ \\
\hline 1993 & $\begin{array}{c}-0.213 * \\
(0.109)\end{array}$ & $\begin{array}{c}-0.291 * * * \\
(0.109)\end{array}$ & $\begin{array}{c}-0.251^{* *} \\
(0.111)\end{array}$ & $\begin{array}{c}-0.241 * * \\
(0.112)\end{array}$ \\
\hline 1997 & $\begin{array}{c}-0.772 * * * \\
(0.104)\end{array}$ & $\begin{array}{c}-0.954 * * * \\
(0.107)\end{array}$ & $\begin{array}{c}-0.938 * * * \\
(0.106)\end{array}$ & $\begin{array}{c}-0.934 * * * \\
(0.106)\end{array}$ \\
\hline 2000 & $\begin{array}{c}-0.845 * * * \\
(0.101)\end{array}$ & $\begin{array}{c}-0.897 * * * \\
(0.103)\end{array}$ & $\begin{array}{c}-0.842 * * * \\
(0.105)\end{array}$ & $\begin{array}{c}-0.833 * * * \\
(0.105)\end{array}$ \\
\hline 2004 & $\begin{array}{c}-0.731 * * * \\
(0.104)\end{array}$ & $\begin{array}{c}-0.772 * * * \\
(0.105)\end{array}$ & $\begin{array}{c}-0.747 * * * \\
(0.105)\end{array}$ & $\begin{array}{c}-0.741 * * * \\
(0.105)\end{array}$ \\
\hline Constant & $\begin{array}{l}-0.199 \\
(0.370)\end{array}$ & $\begin{array}{c}0.920 * * \\
(0.382)\end{array}$ & $\begin{array}{l}0.676^{*} \\
(0.395)\end{array}$ & $\begin{array}{l}0.754^{*} \\
(0.395)\end{array}$ \\
\hline Observations & 11792 & 11762 & 11730 & 11730 \\
\hline Log pseudo-likelihood & -4161.85 & -4010.12 & -4001.80 & -3999.39 \\
\hline Pseudo R-squared & 0.10 & 0.13 & 0.13 & 0.13 \\
\hline
\end{tabular}

Estimation by logistic regression. Coefficients on demographic controls not reported. Robust standard errors in parentheses.

* significant at $10 \%$; * significant at $5 \% ; * * *$ significant at $1 \%$ 
Figure 1. Postwar Turnout

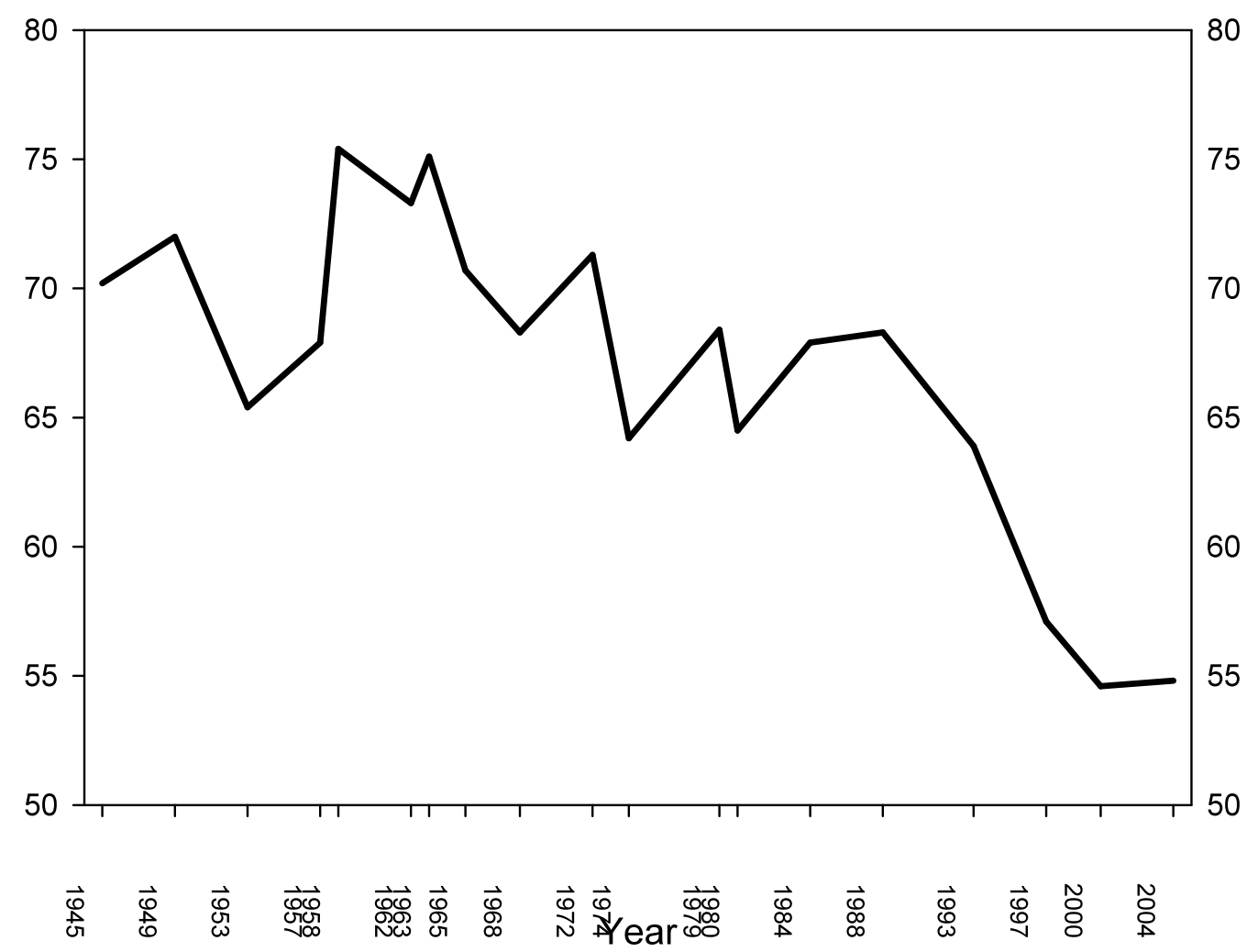


Figure 2. The Stakes
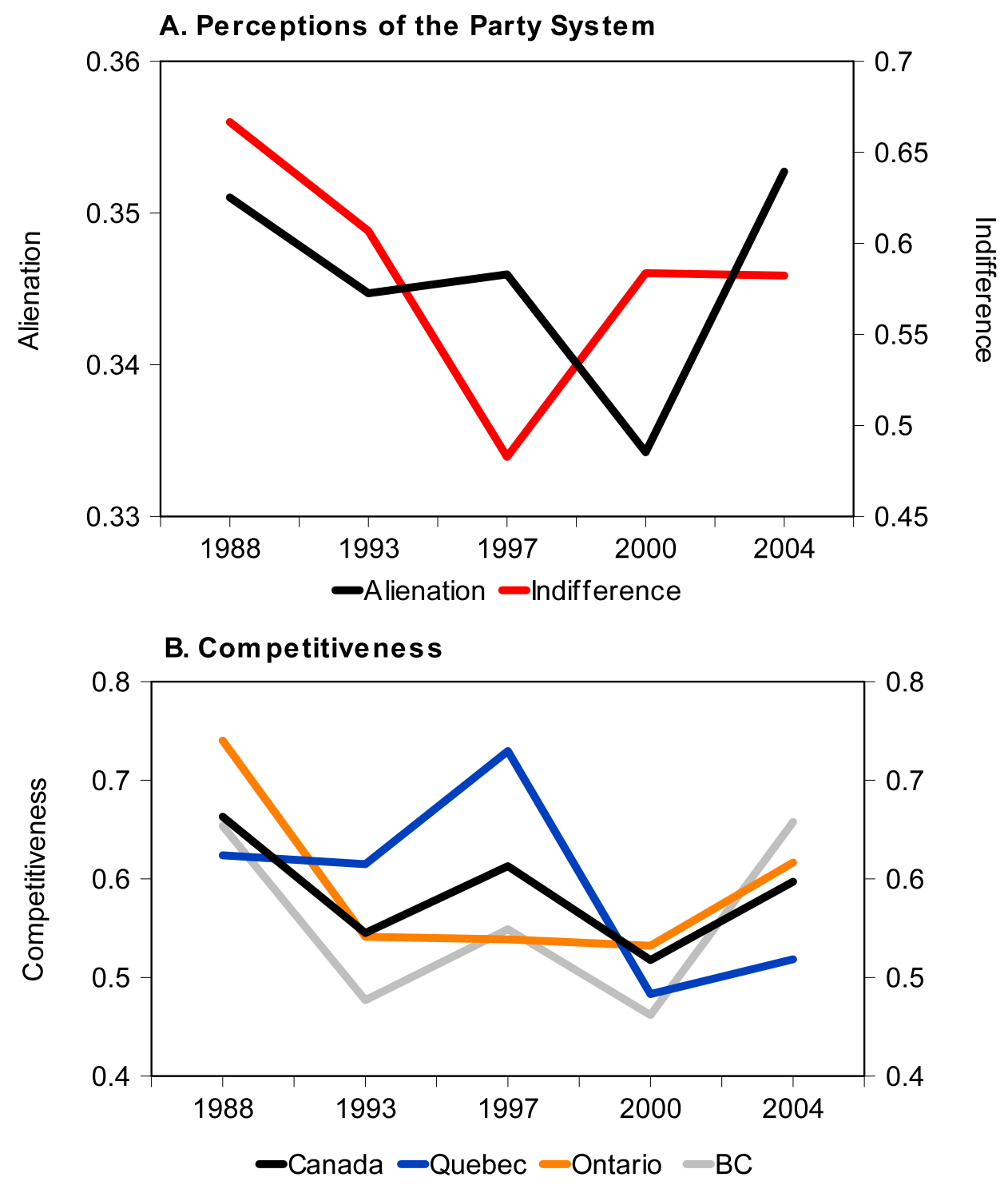
Figure 3. Turnout by Competitiveness for Newly Eligible Voters and Others

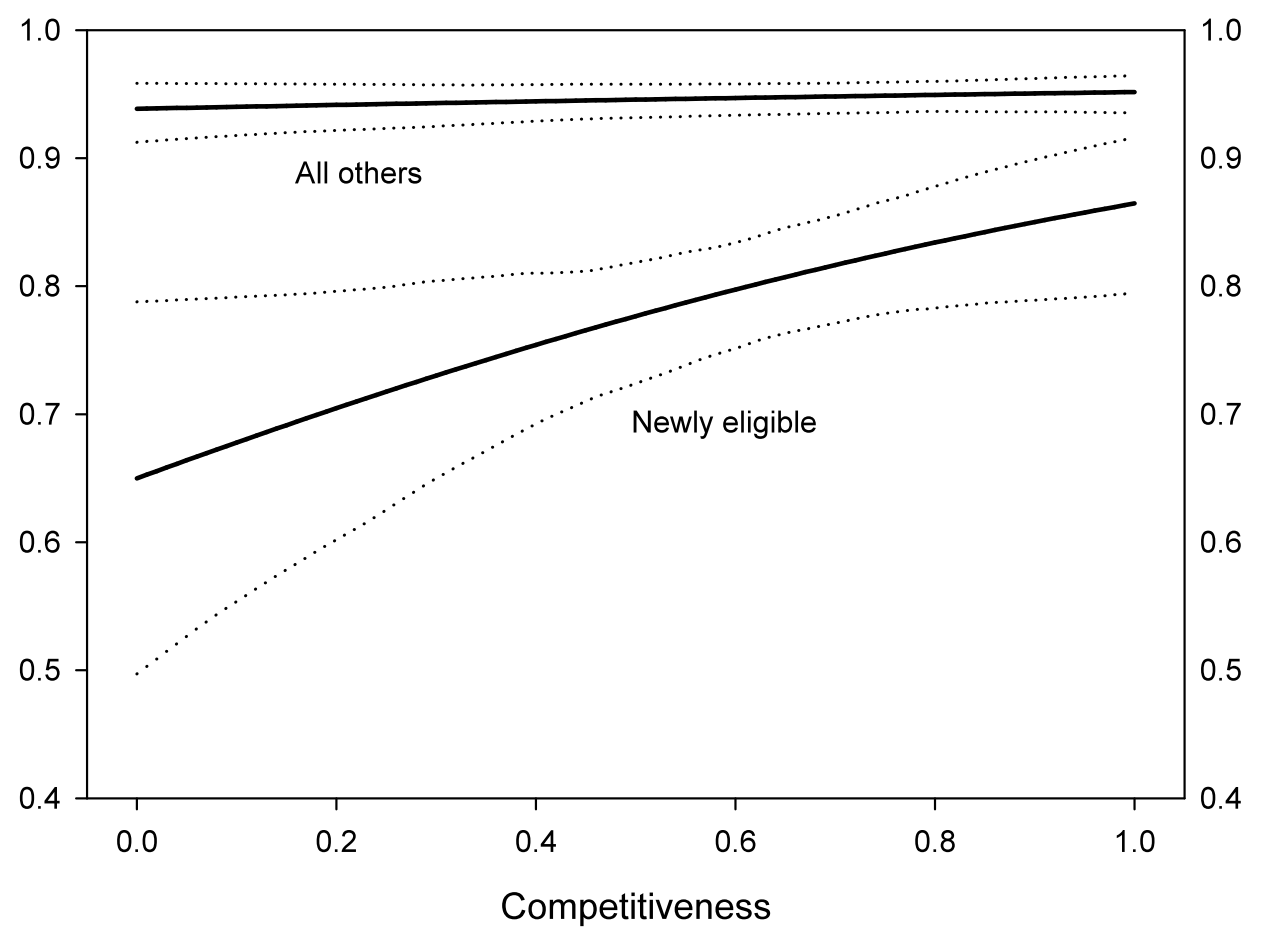




$$
x
$$




\section{References}

Abramson, Paul. 1983. Political Attitudes in America: Formation and Change. W.H. Freeman, San Francisco.

Anderson Barbara A., and Brian D. Silver. 1986. "Measurement and Mismeasurement of the Validity of the Self-Reported Vote." American Journal of Political Science 30: 771-85.

Black, Jerome H. 2005. "From Enumeration to the National Register of Electors: An Account and an Evaluation." Pp. 161_228 in Strengthening Canadian Democracy, edited by P. Howe, R. Johnston, and A. Blais. Montreal: IRPP.

Blais, André. 2000. To Vote or Not to Vote: The Merits and Limits of Rational Choice Theory. Pittsburgh: University of Pittsburgh Press.

Blais, André, and R. Kenneth Carty. 1990. “Does Proportional Representation Foster Voter Turnout?” European Journal of Political Research 18: 167-81.

Blais, André, Elisabeth Gidengil, Neil Nevitte, and Richard Nadeau. 2004. "Where Does Turnout Decline Come From?” European Journal of Political Research 43: 221-236. Brady, Henry, Sidney Verba, and Kay Schlozman (1995). "Beyond SES: A Resource Model of Political Participation.” American Political Science Review 89: 271-294.

Brehm, John. 1993. The Phantom Respondents: Opinion Surveys and Political Representation. Ann Arbor: University of Michigan Press.

Burden, Barry C. 2000. "Voter Turnout and the National Election Studies." Political Analysis 8: 389-98. 
Butler, David, and Donald Stokes. 1969. Political Change in Britain. London: Macmillan.

Carty, R. K., William Cross and Lisa Young. 2000. Rebuilding Canadian Party Politics. Vancouver, BC: UBC Press.

Cox, Gary, and Michael Munger. 1989. "Closeness, Expenditures, and Turnout in the 1982 U.S. House Elections" American Political Science Review 83: 217-231.

Dalton, Russell J. 1999. System Support in Advanced Industrial Democracies. In Pippa Norris, ed., Critical Citizens: Global Support for Democratic Governance. Oxford University Press, New York.

Downs, Anthony. 1957. An Economic Theory of Democracy. New York, Harper.

Endersby, James, Steven Galatas and Chapman Rackaway. 2002. “Closeness Counts in Canada: Voter Participation in the 1993 and 1997 Federal Elections." Journal of Politics 64(2):610-631.

Enelow, James and Melvin Hinich. 1984. The Spatial Theory of Voting. New York: Cambridge University Press.

Franklin, Mark. 2004a. Voter Turnout and the Dynamics of Electoral Competition in Established Democracies Since 1945. Cambridge: Cambridge University Press. . 2004b. "Electoral Competitiveness and Turnout: How Voters React to the Changing Character of Elections." Paper prepared for presentation to the annual meeting of the Midwest Political Science Association, Chicago, IL. 
Gray, Mark, and Miki Caul. 2000. “Declining Voter Turnout in Advanced Industrial Democracies, 1950 to 1997: The Effects of Declining Group Mobilization.”

Comparative Political Studies 33: 1091-1122.

Heckman, James J. 1976. “The Common Structure of Statistical Models of Truncation, Sample Selection, and Limited Dependent Variables and a Simple Estimator for Such Models." Annals of Economic and Social Measurement 5/4: 475-92.

Herring, Cedric. 1989. Splitting the Middle: Political Alienation, Acquiescence, and Activism Among America's Middle Layers. New York: Praeger Publishers.

Highton, Benjamin, and Raymond E. Wolfinger. 2001. "The First Seven Years of the Political Life Cycle.” American Journal of Political Science 45: 202-9.

Howe, Paul. 2004. 'Non-political Sources of Political Disengagement Among the Young," in Canadian Democracy: Bringing Youth Back Into the Political Process. Montréal: Centre for Research and Information on Canada.

Jackman, Robert W. 1987. "Political Institutions and Voter Turnout in the Industrial Democracies.” American Political Science Review 81: 405-23.

\section{[ REFERENCE DELETED ]}

\section{[ REFERENCE DELETED ]}

King, Gary, Michael Tomz, and Jason Wittenberg. 2000. Making the Most of Statistical Analyses: Improving Interpretation and Presentation. American Journal of Political Science 44: 347-61. 
Kingsley, Jean-Pierre. 2004. “An Issue of Paramount Importance.” in Canadian Democracy: Bringing Youth Back Into the Political Process. Montréal: Centre for Research and Information on Canada.

Laakso, Markku, and Rein Taagepera. 1979. "Effective" Number of Parties: A Measure with Application to West Europe. Comparative Political Studies 12: 3-27.

Macke, Anne Statham. 1979. “Trends in Aggregate-Level Political Alienation” The Sociological Quarterly 20: 77-87.

Martinez, Michael D. 2003. "Comment on 'Voter Turnout and the National Election Studies."

Political Analysis 11: 187-92.

McDonald, Michael P. 2003. "On the Overreport Bias of the National Election Study Turnout Rate." Political Analysis 11: 180-6.

McPhee, William N., and Jack Ferguson. 1960. "Political Immunization," in McPhee and William A. Glaser, eds., Public Opinion and Congressional Elections. New York: Free Press, pp. 155-79.

Northrup, David A. 2003. The 2000 Canadian Election Study: Technical

Documentation. Toronto: York University Institute for Social Research.

Plutzer, Eric. 2002. "Becoming a Habitual Voter: Inertia, Resources, and Growth in Young Adulthood," American Political Science Review 96: 41-56.

Riker, William H. and Peter Ordeshook. 1973. An Introduction to Positive Political Theory. Englewood Cliffs, NJ: Prentice Hall. 
Rosenstone, Steven and John Mark Hansen. 1993. Mobilization, Participation and Democracy. New York: MacMillan Publishing Company.

Statistics Canada. 1991. Census of Canada. Public Use Microdata File in Individuals. Obtained from http://data.library.ubc.ca/java/jsp/database/production/detail.jsp?id=231 .

Statistics Canada. 2001. Census of Canada. Public Use Microdata File on Individuals. Obtained from http://data.library.ubc.ca/java/jsp/database/production/detail.jsp?id=906 .

Timpone, Richard J. 1998. "Structure, Behavior, and Voter Turnout in the United States." American Political Science Review 92: 145-58.

Tomz, Michael, Jason Wittenberg, and Gary King. 2003. CLARIFY: Software for Interpreting and Presenting Statistical Results. Version 2.1. Stanford University, University of Wisconsin, and Harvard University. January 5. Available at http://gking.harvard.edu/

Traugott, Michael W. and John P.Katosh. 1979. "Response Validity in Surveys of Voting Behavior." Public Opinion Quarterly 43: 359-77.

Uhlaner, Carole. 1989. "Rational Turnout: The Neglected Role of Groups," American Journal of Political Science 33: 390-422.

Verba, Sidney, Kay Schlozman, and Henry Brady. 1995. Voice and Equality: Civic Voluntarism in American Politics. Cambridge: Harvard University Press.

Wattenberg, Martin P. 2000. Where Have All the Voters Gone? Cambridge, MA: Harvard University Press. 